\title{
Median nerve injury after local injection
}

Amro ahmed fouaad attia* MD.

* Corresponding Author:

Amro ahmed fouaad attia

amrfouad1980@yahoo.com

Received for publication August 18, 2021; Accepted August 30, 2021; Published online August 30, 2021.

Copyright The Authors published by Al-Azhar University, Faculty of Medicine, Cairo, Egypt. Users have the right to read, download, copy, distribute, print, search, or link to the full texts of articles under the following conditions: Creative Commons Attribution-Share Alike 4.0 International Public License (CC BY-SA 4.0).

doi: 10.21608/aimj.2021.91339.1554

${ }^{I}$ Department of Orthopedic, Faculty of Medicine, Al-Azhar University, Cairo, Egypt.

Disclosure: The authors have no financial interest to declare in relation to the content of this article. The Article Processing Charge was paid for by the authors.

Authorship: All authors have a substantial contribution to the article.

\section{INTRODUCTION}

Iatrogenic peripheral nerve injuries, such as injection nerve palsy (INP), have a documented occurrence of $2 \%$ of all peripheral nerve injuries recorded. ${ }^{1-2}$

The peripheral nerve's anatomical laboratory is composed of a varied number of fascicles surrounded by a loose connective tissue called the epineurium. ${ }^{3}$ Each fascicle is surrounded by a multi-layered perineurium, with nerve fibers packed tightly together. ${ }^{3}$ Each nerve fiber is surrounded by the endoneurium, a thin connective tissue sheath. ${ }^{3}$ The perineurium functions as a diffusion barrier (For example, the blood-nerve barrier). ${ }^{4-5}$ It collaborates with the endothelium of endoneurial blood vessels to sustain this barrier and regulate the nerve's intrafascicular milieu. ${ }^{4-5}$

The affected nerve was examined by Kalichman et al., who noted axonal, and myelin degeneration, as well as a thick concentration of inflammatory cells at the nerve injury site. ${ }^{6}$ Additionally, significant endoneurial edema is a significant of that injury. Edema is defined as a structureless region within the

endoneurium in light and electron microscopic examinations. Fluid is only limited to the subperineurial area in normal situations.
Nevertheless, in recorded instances of nerve injury, it is found in all regions of the endoneurial compartment and perineurial spaces of the wounded nerves. ${ }^{6}$

Varity of procedures can be a cause of iatrogenic nerve injuries. In literature reviews of iatrogenic upper limb nerve injuries, the median nerve was the most common nerve that should require surgical procedures. ${ }^{1}$ Carpal tunnel release has been the most popular method that cause median nerve injury which usually partial injury with high incidence with mini-invasive rather than endoscopic procedures, followed by local injection. ${ }^{7} 890 \%$ of cases after local injection were suffered immediatlly. ${ }^{9}$ In the majority of cases, patients had severe pain and severe paresthesias along the median nerve's distribution. ${ }^{7}$ The immediate symptoms start of varying degrees of motor and sensory deficits which has also been documented, but this is still an uncommon manifestation. 9,10. The most likely cause of the instant symptoms is the direct influence of the injection into a nerve ${ }^{9-11}$. Perineural fibrosis is a likely reason of INP's delayed worsening. ${ }^{9}$

The management of those injuries requires these aims. An instant neurological investigation is the 
most important step in acquiring a precise prognosis, which is necessary to acknowledge the mechanical cause of injury, the intensity of the motor, sensory, or both impairments, and further management that should be confirmed by electrophysiological.

In this study, iatrogenic median nerve injuries were prospectively assisted and evaluated with respections to their clinical presentation, injury mechanism, and clinical outcome related to recovery of neurological symptoms and deficits.

\section{PATIENTS AND METHODS}

This prospective study included 8 patients presented with iatrogenic peripheral nerve injuries treated at Orthopedics Department, Al- Azhar University, from 2015 to 2020.

Pain assessment: The neurogenic pain symptom was rated on a $0-10$ visual analog scale (VAS), with 0 indicating no pain and 10 indicating unbearable severe irritating pain. The degree of Hyposthesia and the muscle power chart were graded On the basis of the Medical Research Council's (MRC) scale. All patient had Nerve conduction and EMG to confirm the extent and the degree of nerve injury and to detect any recovery. There are complete nerve injury in 3 patients, and partial injury in 5 patients.

All patients had intensive physiotherapy for preventing muscle wasting by direct muscular electrical stimulation, improving the prognosis, and pain relief until nerve regeneration has occurred or surgery was indicated.

Surgical treatment was offered to the eight patients that failed to respond to medical treatment and physical therapy. Two cases refused surgical intervention and possible management. The remaining 6 cases were treated by surgery intervention, table (1). The surgical management was done in the form of exploration, microscopic assessment of the nerve and its branches. Neuroma excision in all cases of neuroma in continuity, and direct repair or sural nerve cable grafting were done. Intraoperative stimulation of the nerve was helpful to prove that there was no nerve conduction through the neuroma. Figure (1, a, b, c, d ,e and f). Microsurgical Nerves repair was done using, 8-0 or 9-0 nonabsorbable and Fibrin-based glue for coaptation under operating microscope, epineural and perineureal used for nerve coaptation, tension-free repair.

\begin{tabular}{|c|c|c|c|c|c|c|c|c|c|c|c|c|}
\hline NO & Sex & Age & $\begin{array}{l}\text { Injury } \\
\text { case }\end{array}$ & $\begin{array}{l}\text { Pre. } \\
\text { VAS }\end{array}$ & $\begin{array}{l}\text { Pre. } \\
\text { MRC }\end{array}$ & $\begin{array}{c}\text { Time } \\
\text { between } \\
\text { injury } \\
\text { and } \\
\text { surgery }\end{array}$ & $\begin{array}{l}\text { EMG, } \\
\text { NCV }\end{array}$ & $\begin{array}{l}\text { Intraoperative } \\
\text { finding }\end{array}$ & Management & $\begin{array}{l}\text { Post } \\
\text { VAS }\end{array}$ & $\begin{array}{l}\text { Post } \\
\text { MRC }\end{array}$ & $\begin{array}{c}\text { Follow } \\
\text { up } \\
\text { time }\end{array}$ \\
\hline 1 & M & 26 & $\begin{array}{c}\text { Post } \\
\text { local } \\
\text { injection }\end{array}$ & 7 & 4 & 5week & $\begin{array}{l}\text { Complete } \\
\text { injury }\end{array}$ & $\begin{array}{l}\text { Thickening } \\
\text { and debris }\end{array}$ & Nerolysis & 3 & 5 & $10 \mathrm{~m}$ \\
\hline 2 & $\mathbf{F}$ & 19 & $\begin{array}{c}\text { Post } \\
\text { local } \\
\text { injection }\end{array}$ & 8 & 1 & $\begin{array}{c}5 \\
\text { Weeks }\end{array}$ & $\begin{array}{l}\text { Complete } \\
\text { injury }\end{array}$ & neuroma & $\begin{array}{c}\text { Neruroma } \\
\text { excision } \\
\text { Direct } \\
\text { suture. }\end{array}$ & 2 & 4 & $22 m$ \\
\hline 3 & $\mathbf{F}$ & 28 & $\begin{array}{c}\text { Post } \\
\text { local } \\
\text { injection }\end{array}$ & 5 & 2 & $\begin{array}{c}18 \\
\text { weeks }\end{array}$ & $\begin{array}{l}\text { partial } \\
\text { injury }\end{array}$ & $\begin{array}{l}\text { Thickening } \\
\text { and debris }\end{array}$ & Neurolysis & 4 & 4 & $6 \mathrm{~m}$ \\
\hline 4 & $\mathbf{M}$ & 30 & $\begin{array}{c}\text { Post } \\
\text { local } \\
\text { injection }\end{array}$ & 10 & 2 & 11weeks & Not done & Cystic lesion & $\begin{array}{c}\text { Neuroma } \\
\text { excision } \\
\text { and sural } \\
\text { graft }\end{array}$ & 2 & 3 & $3 \mathrm{~m}$ \\
\hline 5 & $\mathbf{F}$ & 37 & $\begin{array}{c}\text { Post } \\
\text { local } \\
\text { injection } \\
\end{array}$ & 10 & 2 & $\begin{array}{c}21 \\
\text { weeks }\end{array}$ & $\begin{array}{l}\text { partial } \\
\text { injury }\end{array}$ & Cystic lesion & $\begin{array}{c}\text { Neuroma } \\
\text { excision and } \\
\text { direct repair }\end{array}$ & 3 & 3 & $10 \mathrm{~m}$ \\
\hline 6 & $\mathbf{F}$ & 32 & $\begin{array}{c}\text { Post } \\
\text { local } \\
\text { injection }\end{array}$ & 10 & 3 & $\begin{array}{c}13 \\
\text { weeks }\end{array}$ & $\begin{array}{l}\text { complete } \\
\text { injury }\end{array}$ & Cystic lesion & $\begin{array}{c}\text { Neuroma } \\
\text { excision and } \\
\text { direct suture }\end{array}$ & 3 & 4 & $20 \mathrm{~m}$ \\
\hline
\end{tabular}

Table 1: Patient analysis.

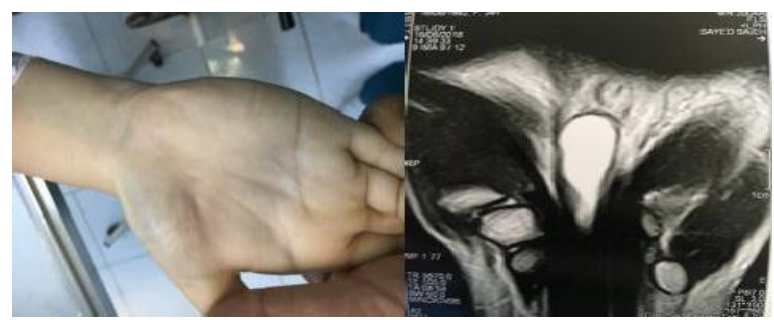

A 


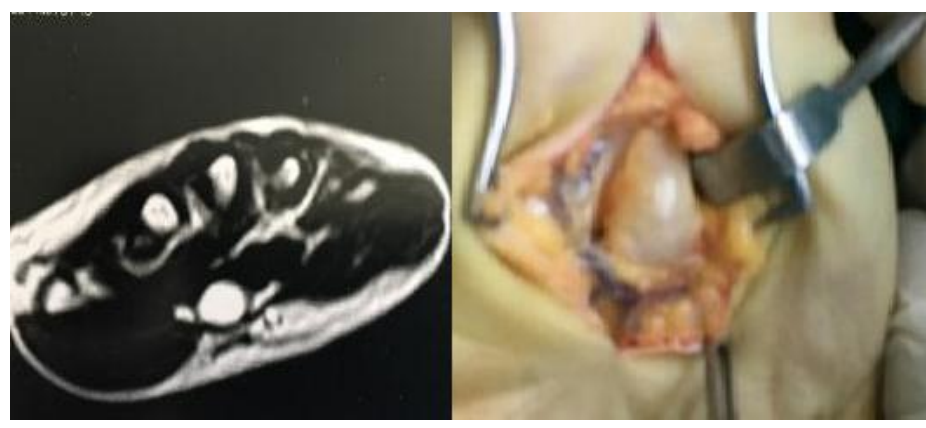

C

$d$

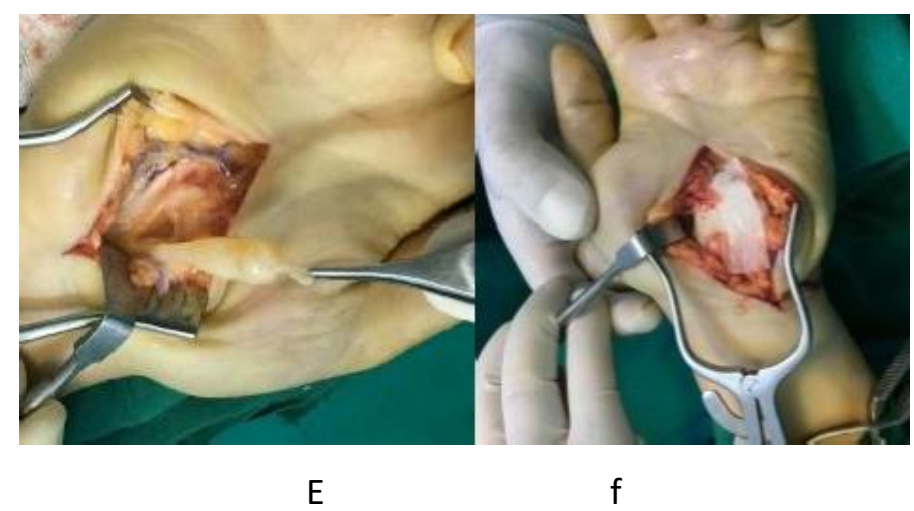

Fig.1: post median nerve local injection.

A neuroma site with thenar wasting, b. and c. MRI Identification of neuroma, d and e. Exploration reveal neuroma, f. after neuroma excision

\section{RESULTS}

The study was done at Hand and reconstructive microsurgery unit, Al-Azhar university Hospitals, there were 8 patients, 2 male $(33.3 \%)$ and 4 females (66.6\%) with mean age 28.7 years (average from 19 to 37) with mean follow up time was (11.83 months). Intraoperative finding; there were a cystic lesion in 3 cases, neuroma in one case, and granuloma with debris in 2 cases. Surgical management ranged form of neurolysis in 2 patients, neurolysis and neuroma resection in 3 patients with end to end suture and sural graft in one patient after neuroma excision.

There was significant improvement in pain score, the mean VAS improved from 8.3 preoperatively to 2.8 postoperatively and improvement of MRCS from 2.3 to 3.8 , and improvement of paraethesia, with total function outcome improvement. Direct suture had a good prognosis and recovery than graft. Earlier interference gave a good prognosis rather than late one.

\section{DISCUSSION}

The Median nerve, are affected during Carpal tunnel release and local injection around the wrist and venous injection around the elbow are usually implicated for injuring this nerve. Which account around $3.6 \%$ of all reported cases of iatrogenic nerve palsy, always after local injection which are associated with shooting pain sensation which must be stopped immediately. There are reported cases of median nerve granuloma between fascicles, white precipitate with thickening of epineurium. ${ }^{14,15,16}$

Injection-related peripheral nerve injury is an iatrogenic problem that ranges from $1.5 \%$ to as high as $15 \%$. A high incidence in the developing world than developed one. ${ }^{19-20}$

In literature, the early presentation of the patients, post brachial blocks and intravenous injection-related nerve palsies, a more severe neurogenic pain and neurological deficits, In contrast to the intramuscular injection injury group of patients, motor weakness was more common than severe sensory symptoms, which propelled them towards physical therapy. ${ }^{20}$

Despite the fact that steroid injections are commonly used to treat CTS, the most common side effect is direct needle injury to the median nerve. The injection's safest location is still up for debate. A number of incidences of median nerve injury have been recorded during CTS injection. ${ }^{21}$ The use of ultrasonography and nerve stimulator during local injection may reduce the incidence of that complications as well as during local injection of trigger finger, median nerve, and de Qurvan tenosynovitis $^{22}$

All medications when injected directly into the nerves are potentially more damaging to the myelin sheath and axons. In contrast, these medications cause less neurological damage when they are 
injected in the perineural tissue or adjacent muscle mass. ${ }^{23}$

Linskey and Segal in 1990 were published a case study of that injury ${ }^{11}$. It was shown that a local injection of $1 \mathrm{ml}$ of methylprednisolone suspended in polyethylene glycol and $0.5 \%$ bupivacaine hydrochloride caused a lesion of nerve injury. During the injection, the patient felt "a new type of pain" (not related to CTS) going down his hand to the median nerve distribution; after the carpal tunnel was released, they discovered opaque white foreign material inside the epineurium. A similar white precipitate has been seen within multiple nerve fascicles during the epineurectomy procedure. Posch and Marcotte, who exhibited the same picture, had previously documented such thickening. ${ }^{14}$ The plaque was dubbed a "median nerve granuloma" by the researchers. 15

Among the drugs injected, methylprednisolone was shown to be intermediately toxic $\underline{15}$. Despite the fact that bupivacaine is one of the least toxic local anesthetics, it could induce significant axonal degradation $\underline{23}$. Proof of the neurotoxicity of the polyethylene glycol wherein the methylprednisolone has been suspended has been found by Chino et al., Combes and Clark in one study, and Linskey and Segal in another study. $\underline{.2425}$ And they discover that methylprednisolone is the major reason of the patient's injection palsy. ${ }^{11,23}$.

Injection site is still controversial, but some literature suggests it should be ulnar to the palmaris longus tendon. If there is no palmaris longus, the injection must be done in line with the fourth digit. ${ }^{11}$ with special emphasis to the needle location and orientation. The tip of the needle must be placed outside the nerve and beneath the transverse carpal ligament. The subjective response of the patient is important, during injection. And must be ceased promptly when there is abnormal pain or paresthesia. So, Racasan and Dubert ${ }^{21}$ identified median nerve irritation after carpal tunnel injection as a common condition, as well as the facts that the median nerve for most hands reaches ulnar to the palmaris longus tendon. They reported same anatomical plane for injection as previous one, as well as the flexor carpi ulnaris tendon is the safest place to inject. ${ }^{21}$ with recommendation of use US- guided injection to allow the doctor to access the carpal tunnel without damaging nearby tissue and to visualize the injected substance's distribution. Furthermore, the physician can modify the distance between the needle and the median nerve. This allows for greater needle control and a more accurate perineural injection. ${ }^{21}$

Debates continue regarding when intervention is necessary and, if it is needed, immediately or not. To determine if there is spontaneous healing or not, a three to six-month monitoring period is prescribed. This could then be employed to determine if further intervention is required ${ }^{11}$. During follow up if there is no recovery or the case become more worst, the surgical interference is mandatory.

We had reported 6 cases of median nerve injurypostinjection with severe sensory and motor neurological insult revealing granulomatous nerve changes, and need surgical interference. In our series, the neurogenic pain, parasthesia and motor weakness were of immediate onset in a majority of patients following the local injection.

Electrophysiological study (EMG-NC), There were complete nerve injury in 3 patients, and partial injury in 5 patients. Intraoperative nerve stimulation is very important during surgery, It may reveal a good conduction or not. if NAP is not demonstrated across the injured nerve, excision of the damaged segment and a nerve cable grafting should be ideally performed, this also have been described by other authors ${ }^{27}$. Regarding to intraoperative finding, there were cystic lesion in 3 cases, neuroma in one case and thickening and granuloma in 2 patients. There were a good function recovery for patients with direct nerve suture and early intervention within 3 months from the time of injury.

About side to side suture or nerve graft, Neurolysis or side to side nerve suture were superior in functional outcome than the nerve grafting procedures. These findings were consistent with the literature review. ${ }^{28}$ The sensory recovery is more promising than the motor one in complete nerve injury.

This research has some limitations, the first is that research employed a tiny sample size; to verify the differences between instances, more patients would be needed.

\section{CONCLUSION}

An iatrogenic median nerve injury is not an uncommon problem. Corticosteroids are the main harmful drug to the nerve, early diagnosis, an early intervention at specialized center are important factors that can provide an encouraging outcome, and decrease patient complications, In majority of the cases, the problem can be avoided by having a thorough anatomical knowledge with US-guided injection, which is more safe and effective than blind injection.

\section{REFERENCES}

1. Isolated injection injury to the posterior femoral cutaneous nerve. Iyer VG, Shields CB. http://journals.lww.com/neurosurgery/Abstract/1 989/11000/Isolated_Injection_Injury_to_the_Posterio r_Femoral.27.aspx. Neurosurgery. 1989;25:835-8.

2. Nerve injuries following intramuscular injections: a clinical and neurophysiological study from Northwest India. Pandian JD, Bose S, Daniel V, et al. J PeriphNervSyst. 2006;11:165-71.

3. Key A, Retzius G. Stockholm. II. Samson and Wallin; 1876. Studies in der anatomie des nervensystems und des bindegewebes; pp. 102-112.

4. Studies on vascular permeability in peripheral nerves. I. Distribution of circulating fluorescent serum albumin in normal, crushed and sectioned rat sciatic nerve. Olsson Y. Acta Neuropath. 1966;7:1 
5. The perineurium as a diffusion barrier to protein tracers following trauma to nerves. Olson $\mathrm{Y}$, Kristensson

K. https://www.ncbi.nlm.nih.gov/pubmed/4700610. Acta Neuropath. 1973;23:105.

6. Pathology of local anesthetic-induced nerve injury. Kalichman MW, Powell HC, Myers RR. Actaneuropathol. 1988;75:583-9

7. Zhang J, Moore AE, Stringer MD. Iatrogenic upper limb nerve injuries: a systematic review. ANZ J Surg. 2011;81(4):227-36.

8. Kretschmer T, Antoniadis G, Braun V, Rath SA, Richter HP. Evaluation of iatrogenic lesions in 722 surgically treated cases of peripheral nerve trauma. $J$ Neurosurg. 2001;94(6):905-12.

9. Injection nerve palsy. Kakati A, Bhat D, Devi BI, et al. J Neurosci Rural Pract. 2013;4:13-8

10. Injection injury to the median nerve. Fremling MA, Mackinnon SE. https://www.ncbi.nlm.nih.gov/pubmed/?term=Fr emling+MA\%2C+Mackinnon+SE. Ann PlastSurg. 1996;37:561-7.

11. Median nerve injury from local steroid injection in carpal tunnel syndrome. Linskey ME, Segal R. https://www.ncbi.nlm.nih.gov/pubmed/?term=Lin skey+ME\%2C+Segal+R. Neurosurgery. 1990;26 :512-5.

12. Baumann SB, Welch WC, Bloom MJ. Intraoperative SSEP detection of ulnar nerve compression or ischemia in an obese patient: A unique complication associated with a specialized spinal retraction system. Arch Phys Med Rehabil 2000;81:130-2.

13. Warrender WJ, Oppenheimer S, Abboud JA: Nerve monitoring during proximal humeral fracture fixation: What have we learned?. Clin Orthop Relat Res. 2011;469: 2631-7.

14. Carpal tunnel syndrome: an analysis of 1201 cases. Posch JL, Marcotte DR. http://journals.lww.com/plasreconsurg/Citation/ 1977/01000/Carpal_tunnel_syndrome_an_analysis_ of_1,201.58.aspx. Orthop Rev. 1976;5:25-35.

15. Peripheral nerve injection injury with steroid agents. Mackinnon SE, Hudson AR, Gentili F, et al. https://www.ncbi.nlm.nih.gov/pubmed/?term=Ma ckinnon+SE\%2C+Hudson+AR\%2C+Gentili+F.Plast ReconstrSurg. 1982;69:482-90.

16. Median nerve injury from local steroid injection in carpal tunnel syndrome. Linskey ME, Segal R. https://www.ncbi.nlm.nih.gov/pubmed/?term=Lin
skey+ME\%2C+Segal+R. Neurosurgery. 1990;26: $512-5$.

17. Orgel MG: Epineurial versus perineurial repair of peripheral nerves. Clin Plast Surg .1984;11:101-4.

18. Sameem M, Wood TJ, Bain JR: A systematic review on the use of fibrin glue for peripheral nerve repair. Plast Reconstr Surg .2011;127:2381-90.

19. Ahuja B. Post injection sciatic nerve injury. Indian Pediatr .2003;40:368-9.

20. Yeremeyeva E, Kline DG, Kim DH. Iatrogenic sciatic nerve injuries at buttock and thigh levels: The Louisiana State University experience review. Neurosurgery .2009;65:63-6.

21. Racasan O, Dubert T. The safest location for steroid injection in the treatment of carpal tunnel syndrome. J Hand Surg Br. 2005;30:412-4

22. Zhou Y, Zhao Y, Lin HH, Wang TL. Comparison of blockage effect of axillary brachial plexus block between ultrasound guidance alone and ultrasound guidance plus neurostimulation. Zhonghua Yi Xue Za Zhi .2013;93:1649-52

23. Strasberg JE, Atchabahian A, Strasberg SR, Watanabe O, Hunter DA, Mackinnon SE. Peripheral nerve injection injury with antiemetic agents. $J$ Neurotrauma .1999;16:99-107.

24. Pathology of propylene glycol administered by perineural and intramuscular injection in rats. Chino N, Awad EA, Kottke FJ. https://www.ncbi.nlm.nih.gov/pubmed/?term=Ch ino+N\%2C+Awad+EA\%2C+Kottke+FJ. Arch Phys Med Rehabil. 1974;55:33-8

25. Sciatic nerve injury following intragluteal injection: pathogenesis and prevention. Combes MA, Clark WK. Am J Dis Child. 1960;199:579.

26. Wani M, Sheikh S, Ahmed A. Clinical, electrophysiological, and prognostic study of postinjection sciatic nerve injury: An avoidable cause of loss of limb in the peripheral medical service. Ann Indian Acad Neurol . 2009;12:116-9.

27. Esquenazi Y, Park SH, Kline DG, Kim DH. Surgical management and outcome of iatrogenic radial nerve injection injuries. Clin Neurol Neurosurg .2016;142:98-103

28. Boeson MB, Hranchook A, Stoller J. Peripheral nerve injury from intravenous cannulation: A case report. AANA J . 2000;68:53-7. 